\title{
BMJ Open Impact of changes in pill appearance in the adherence to angiotensin receptor blockers and in the blood pressure levels: a retrospective cohort study
}

\author{
B Lumbreras, ${ }^{1,2}$ E López-Pintor ${ }^{3}$
}

To cite: Lumbreras B, LópezPintor E. Impact of changes in pill appearance in the adherence to angiotensin receptor blockers and in the blood pressure levels: a retrospective cohort study. BMJ Open 2017;7:e012586. doi:10.1136/bmjopen-2016012586

- Prepublication history for this paper is available online. To view these files please visit the journal online (http://dx.doi.org/10.1136/ bmjopen-2016-012586).

Received 10 May 2016 Revised 26 January 2017 Accepted 3 February 2017

CrossMark

\footnotetext{
${ }^{1}$ Department of Public Health, History of Science and Gynecology, Miguel Hernández University, Alicante, Spain ${ }^{2}$ CIBER en Epidemiología y Salud Pública (CIBERESP), Madrid, Spain

${ }^{3}$ Department of Engineering, Area of Pharmacy and Pharmaceutical Technologies, Miguel Hernández University, Alicante, Spain
}

Correspondence to Dr B Lumbreras; blumbreras@umh.es

\section{ABSTRACT}

Objective: To assess the level of adherence to angiotensin receptor blockers (ARBs) in patients regularly attending a community pharmacy and the influence of a change in patients' adherence to pharmacological treatment.

Design: Retrospective cohort study of a random sample of consecutive patients collecting their medication.

Setting: 40 community pharmacies in Alicante (Southeast Spain).

Participants: 602 consecutive $\geq 18$ years old patients following treatment with ARBs at least 3 previous refills were included.

Main outcome measures: Prevalence of uncontrolled blood pressure (BP) and adherence to prescribed pharmacological treatment (measured through both the Batalla and the Morisky-Green tests). A multivariate Poisson regression model was used to estimate the adjusted risk ratio ( $\mathrm{RRa}$ ) for nonadherence to pharmacological treatment by the presence of a change in patient's adherence and other significant variables.

Results: 161/602 (13.7\%) patients presented uncontrolled BP. According to the Morisky test, 410/ $602(68.2 \%)$ patients were considered adherent to pharmacological treatment and 231/602 (38.4\%) patients according to the Batalla test. According to the Morisky-Green test, in the multivariable analysis, patients with a previous change in pill appearance were less likely to be adherent than those patients with no change in their pharmacological treatment (RRa 0.45; CI $95 \% 0.22$ to $0.90 ; p=0.024)$. Systolic BP was higher in patients with a change in pill appearance in the previous 3 refills (median BP 142 mm Hg; IQR 136148 ) than in those who did not have a change (median BP 127 mm Hg; IQR 118-135; $p<0.001$ ).

Conclusions: There was a low percentage of adherence and nearly $15 \%$ of uncontrolled BP in patients who regularly collected their medication. Switching between pills of different appearances was associated with lower patient adherence to pharmacological treatment and a higher uncontrolled BP than no change in pharmacological treatment or change only in package but not in pill appearance.

\section{Strengths and limitations of this study}

- This is the first study that evaluates the impact of a change in pill appearance on individual patient adherence in patients considered as persistent with pharmacological treatment.

- The strength of this study is that it evaluates how patients' adherence is affected both by pill appearance and changes in the coating or filler.

- We used indirect tests such as the Morisky-Green test and the Batalla test to assess adherence. These are not ideal tests, but we included the blood pressure measurement as a health impact index.

\section{INTRODUCTION}

Angiotensin receptor blockers (also known as ARBs) are a pharmacological treatment widely used for patients with high blood pressure (BP), kidney disease and heart failure. The National Institute for Health and Care Excellence (NICE) 2011 guidelines recommend that ARBs (of low acquisition cost) should be considered as an equal first-line option alongside ACE inhibitors in patients aged $<55$ years, and as an alternative pharmacological treatment for those who are unable to continue ACE inhibitors therapy due to intolerance. ${ }^{1}$ Nevertheless, the problem with the treatment is the lack of adherence. A previous cohort study of 21723 patients who had recently started antihypertensive pharmacological treatment with ARBs showed that the first year continuation rate was $64 \%^{2}$ and a previous meta-analysis $^{3}$ showed the adherence to ARBs as $61 \%$.

One of the important factors related with adherence is generic substitution. ${ }^{4}$ In some countries, like Spain, generic substitution is allowed and their governments encourage doctors to prescribe them. Pharmacists can make a substitution between generics, choosing 
one from those available in the national system of reference prices, unless the doctor and/or the patient prefer another product. A problem arises when this substituted drug is of a different shape, size or colour from the previous one, which can confuse the patient and contribute to a lack of adherence. ${ }^{5}$ According to the European Medicines Agency, a generic medicine contains the same active substance(s), is used at the same dose(s) and treats the same disease(s) as the reference medicine. Moreover, bioequivalence studies are carried out for medicines that are absorbed by the body before being released into the bloodstream. However, the US Food and Drug Administration (FDA) does not require generic drugs to be a different colour or shape to each other or their brand name versions. ${ }^{6}$ The FDA has recently shown a marked interest in how the colour, shape or size of generic drugs affects the patients' adherence to pharmacological treatment regimens. ${ }^{7}$

Two previous studies have assessed the influence of the variation in pill appearance on non-persistence among commercially insured patients in the USA. ${ }^{8} 9$ These studies considered a patient as non-persistant when he/she did not collect the medication within a particular number of days after the prescription date and they concluded that changes in pill colour significantly increased the odds of non-persistance. However, the fact that a prescription was filled does not prove that the patient actually took the medication. Therefore, these studies did not distinguish between those patients who did not fill the prescription and those who did so but did not take it. The factors associated with both situations could be different, as could the potential interventions to improve the adherence to pharmacological treatment.

In countries like the USA, a defined quantity of tablets, pills, etc, are prescribed for each individual patient and placed in transparent, generic bottles, according to the patients' pharmacological treatment and its duration. In contrast, in Spain, as in other European countries, the drugs are prescribed in their original package. The problem arises because the packages for each drug are always different, even in 'concordant' pharmacological treatments (matching pill shape and colour), which can also confuse the patient. Hence, when assessing the influence of a change in pill appearance on patient adherence, it is essential to distinguish between those patients who have received a different package (but matching pill shape and colour) and those who have received both a different package and a change in pill appearance.

Most of the studies evaluating adherence to ARBs included patients after hospitalisation ${ }^{10}$ or assessed adherence through the failure to collect a prescription. ${ }^{11}$ However, given that most of the patients in pharmacological treatment with ARBs are attended in primary care centres, we decided to carry out the study in the community pharmacies where patients collect their medication. Moreover, as medication experts in primary care, community pharmacists are in an ideal position to address compliance and persistence issues in people with hypertension. ${ }^{12}$ Another important factor that appears to be related to patient adherence with pharmacological treatment is the level of patients' satisfaction with pharmacological treatment, ${ }^{13}$ which could also help clinicians to predict pharmacological treatment compliance, and consequently, to take clinical decisions.

Thus, we sought to assess the level of adherence to ARBs in patients regularly attending a community pharmacy, the influence of a change in patients' medication (package, and/or pill appearance) on their adherence to pharmacological treatment and the associated health impact.

\section{METHODS}

Design

We performed a retrospective cohort study of a random sample of consecutive hypertensive patients collecting their medication (ARBs treatment) from a random sample of community pharmacies in Alicante (Southeast Spain). These patients were following pharmacological treatment with one of the selected drugs for at least three refills before the inclusion date, according to the pharmaceutical electronic register. This register belongs to the Regional Health Service and was created to improve the prescription and dispensation of medication. It represents a link between community pharmacies and primary care centres, allowing pharmacists to know the medical prescription of each individual patient. The collecting period was carried out from March 2015 to July 2015.

We classified each patient according to the changes in his/her three previous refills (collected from the pharmacy electronical register) in the following three groups: (1) no change (same package and appearance); (2) matched change (different package and 'concordant' appearance) or (3) no matched change (different package and 'discordant' appearance). All the brand name and generic drug presentations of the ARBs medication were classified in different groups depending on their pill appearance.

\section{Patient population}

We included a sample of consecutive $\geq 18$ years old patients following pharmacological treatment with one of the ARBs selected drugs (candesartan, candesartan/ hydrochlorothiazide, valsartan, valsartan/hydrochlorothiazide, telmisartan, telmisartan/hydrochlorothiazide, irbesartan or irbesartan/hydrochlorothiazide) for the three previous refills.

The exclusion criteria were: (1) patients unable to complete the questionnaires because of severe physical or mental disability or people who were not autonomous in the administration of their medication; (2) patients living in nursing homes; (3) patients discharged from 
hospital <4 weeks prior to recruitment; (4) pregnant women; and (5) individuals simultaneously taking other antihypertensive medications or medications for chronic heart failure or angina.

Sample size calculation: According to a previous meta-analysis, ${ }^{3}$ the adherence to ARBs was $64 \%$. For the evaluation of adherence to antihypertensive medication in the patients included in our study, at least 355 patients were required to have a precision of $5 \%$. According to a previous study evaluating generic drugs among patients with cardiovascular disease after myocardial infarction, ${ }^{9}$ the odds of non-persistence in patients increased by $66 \%$ after a change in pill shape and $29 \%$ of the patients had a variation in pill appearance. We increased this number to 600 patients to evaluate the odds of variation in pill appearance in adherent and non-adherent patients.

\section{Eligibility criteria of community pharmacies}

We selected 602 patients to be included in the study from 40 community pharmacies randomly selected out of the 684 in the province of Alicante (each community pharmacy consecutively included the first 15 patients that fulfilled the selection criteria).

We selected a pharmacist in charge of each community pharmacy who agreed to participate and was available to interview the patients. A general meeting was organised in the Faculty of Pharmacy at the University Miguel Hernandez in February 2015. In this meeting, we detailed the main aim of the study and the procedure. The pharmacist in charge of each community pharmacy also attended training seminars focused on the following key topics: medication adherence; medication management for cardiovascular risk factors; research methods to collect data; pharmacovigilance and good clinical practices. A pharmacist with experience in clinical studies, regularly monitored each community pharmacy and validated each patient's questionnaire before it was included in the study.

\section{Data collection}

Adherence was assessed through two self-reported methods: the Batalla test ${ }^{14}$ and the Morisky-Green test. ${ }^{15}$ The Batalla test provides information about the patients' understanding of their illness. The questions, adapted to high BP, used in this study were as follows: (1) Is high BP a lifelong disease? (2) Can you control this disease by diet and/or with medication? and (3) Mention one or more organs that can be damaged by high BP. A patient was considered adherent if he/she was able to answer these three questions suitably. The Morisky-Green test comprises four yes/no questions: (1) Have you ever forgotten to take your medicine? (2) Are you sometimes careless about the time you take your medicine? (3) Do you ever stop taking your medicine when you feel better? (4) Do you ever stop taking your medicine if you feel worse? A person was considered to be non-adherent if he/she responded affirmatively to at least one question.
As the Morisky test is validated in Spain to assess the adherence to hypertensive pharmacological treatment, it was selected as the reference method.

$\mathrm{BP}$ was also measured as a health impact index to reduce the bias resulting from the use of previous tests. Following the European Society of Hypertension (ESH) and of the European Society of Cardiology (ESC) guidelines ${ }^{16}$ the pharmacist tested the patients' BP with a validated and calibrated sphygmomanometer on the upper arm with the cuff at heart level, with the patient in the sitting position. The patient was tested at the end of the interview after at least $10 \mathrm{~min}$ of rest. The average of two measurements was taken 2-3 min apart but when systolic BP measurements differed by $10 \mathrm{~mm} \mathrm{Hg}$ or more, or diastolic BP differed by $6 \mathrm{~mm} \mathrm{Hg}$ or more, a third reading was taken. In this instance, the average of the two closest systolic and two closest diastolic BP measurements was used to define the BP. Uncontrolled BP was defined as average systolic BP and/or diastolic $\mathrm{BP} \geq 140$ and/or $\geq 90 \mathrm{~mm} \mathrm{Hg}$, respectively.

We also collected, through a structured questionnaire, (1) sociodemographic variables: sex, nationality, marital status and educational level; (2) clinical variables: previous cardiovascular event, other comorbidities; and (3) medication-related variables: history of ARBs use, other concomitant medications, how the patients kept the medication (in its original medication container or package, with the blister pack or in a pill organiser) and knowledge of the ARB indication. Patients also completed the "Treatment Satisfaction Questionnaire for Medication' (TSQM), ${ }^{17}$ a questionnaire designed for use with chronic patients undergoing pharmacological treatment for any disease. It measures the pharmacological treatment satisfaction and is structured in six dimensions: pharmacological treatment effectiveness, convenience of use, impact on daily living/activity, medical care, undesirable side effects and global satisfaction. The items were scaled on a five-point bipolar scale from 'extremely dissatisfied' to 'extremely satisfied'.

Both adherence tests, together with the other sociodemographic, clinical and medication-related variables, were included in the general questionnaire, which was administered at the beginning of the visit.

\section{Statistical analysis}

All data were computerised anonymously and purified. Statistical precision was determined through the calculation of $95 \%$ CIs using the appropriate method according to the type of measurement and the available data. All analyses were carried out with the statistical programmes $\mathrm{R}$.

A descriptive analysis was made of all the study variables, calculating the median, IQR, total frequency and relative frequency of each category; 95\% CIs were calculated for the proportions. We considered the Morisky-Green test to be the reference method for assessing adherence. The crude risk ratios (RRs) and their 95\% CIs were calculated to measure the association 
between each included variable and adherence. A multivariate Poisson regression model was built applying a stepwise procedure to enter variables in the model. The following independent variables were included in the model: nationality, number of drugs per patient, duration of pharmacological treatment, how the patients stored the medication, impact of undesirable adverse effects on leisure activities and convenience of medication use frequency.

\section{RESULTS}

\section{Sample characterisation}

According to figure 1, out of the 672 patients assessed for eligibility $4(0.6 \%)$ were excluded. Of the 668 $(99.4 \%)$ who fulfilled the selection criteria, $662(90.1 \%)$ patients were finally included.

Sociodemographic variables: The median age was 68.8 years old (IQR 69.9-76.9), 302/602 (50.0\%) were men, $573 / 602$ were Spanish $(95.2 \%)$, had primary studies $(245 / 602,40.7 \%)$ and were married (393/602, $65.3 \%$; table 1 ).

Clinical variables: The patients reported a median intake of 4 medications/day (IQR 2-6; not including ARB treatment), a median number of 2 diseases/patient (IQR 1-3; not including hypertension) and 108/602 $(17.9 \%)$ patients had a cardiovascular event in the past. Valsartan or valsartan plus hydrochlorothiazide were the most frequently used ARB treatments $(261 / 602,43.4 \%)$, $548 / 602(91.0 \%)$ patients were in ARB treatment for more than 1 year and the majority correctly identified the ARB treatment indication $(565 / 602,93.9 \%)$. The majority of the patients kept the medicine in its original package $(471 / 602,78.2 \%), 74 / 602(12.3 \%)$ in a pill organiser and $57 / 602(9.5 \%)$ with the blister pack (table 2).

Questions regarding satisfaction with medication: More than $90 \%$ of the patients reported that the side effects did not affect their physical, leisure or daily living

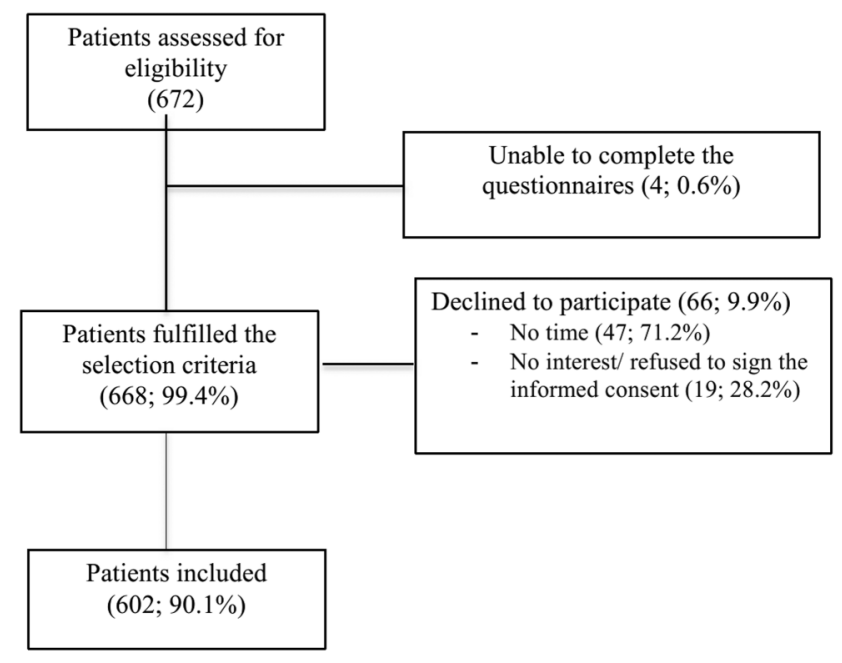

Figure 1 Flow diagram showing the procedure selection of the study participants. activities, but $35 \%$ of them stated that the pharmacological treatment impacted greatly on those activities. More than 30\% reported that the pharmacological treatment was very effective and nearly $70 \%$ were satisfied with the pharmacological treatment. Almost $14 \%$ of the patients reported that their doctors did not explain the characteristics of the disease to them properly (table 3).

Adherence measures: According to the Morisky test, 410/ $602(68.2 \%)$ patients were considered adherent to pharmacological treatment and 231/602 (38.4\%) patients were considered adherent to pharmacological treatment according to the Batalla test. Out of 602 patients, $161(13.7 \%)$ presented high levels of BP (uncontrolled BP).

\section{Variables associated with adherence to treatment}

Prevalence of adherence using the Morisky-Green test was higher in Spanish patients than in patients of other nationalities $(396 / 573,69.1 \%$ vs $14 / 29,48.3 \%$, $p=0.019$; table 1). Prevalence of adherence was also higher in patients in pharmacological treatment with $\geq 5$ drugs than in those with $<5$ drugs $(147 / 188,78.2 \%$ vs 263 / $414,63.5 \%, \mathrm{p}<0.001)$, and it was lower in patients in pharmacological treatment for 6 months to 1 year (12/ $27,44.4 \%)$ than in those patients in pharmacological treatment for $<6$ months $(24 / 26,92.3 \%)$ or $>1$ year $(374 / 548,68.2 \%$; $\mathrm{p}=0.002$; table 2$)$. The prevalence of adherence was higher in those patients reporting that the presence of adverse effects did not interfere with their leisure activities (391/559, 69.9\% vs $168 / 559$, $30.1 \% ; \mathrm{p}=0.004)$. The patients also had a high prevalence of adherence when they considered the frequency of medication use comfortable, $(287 / 398,72.1 \%$ vs 111 / 398, 27.9\%; $\mathrm{p}=0.032$; data not shown).

Prevalence of adherence using the Batalla test was higher in patients with a higher educational level $(51 / 93,54.8 \%$ in patients with university studies; $63 / 146,43.2 \%$ in patients with secondary studies; $81 / 245,33.1 \%$ in patients with primary studies; and $27 / 116,23.9 \%$ in patients without studies; $\mathrm{p}<0.001)$. Those patients with controlled BP showed a higher prevalence of adherence than those with uncontrolled BP (174/441, 39.5\% vs 49/161, 30.4\%; $\mathrm{p}=0.042)$. Those patients who reported having had an adverse effect had a lower prevalence of adherence in comparison with those who had not (6/30, $20 \%$ vs $217 / 572,37.9 \%$; $p=0.047)$. Those patients reporting that the medical doctor detailed the importance of the pharmacological treatment had a higher prevalence than those who did not $(127 / 389,37.5 \%$ vs $12 / 65,15.6 \%$; $\mathrm{p}<0.001)$.

\section{Impact of changes in pharmacological treatment on the patient's adherence to pharmacological treatment}

Out of 602 patients, $66(11.0 \%)$ had undergone a change in their pharmacological treatment in the previous three refills; $28(4.7 \%)$ a change only in the medication package and $38(6.3 \%)$ in the medication package and the pill appearance. 
Table 1 Description of the sociodemographic characteristics of the patients included in the study according to the adherence to treatment (according to Morisky-Green test)

\begin{tabular}{|c|c|c|c|c|}
\hline Variable & Total & Non-adherent & Adherent & p Value \\
\hline Sex & & & & 0.221 \\
\hline Men & 301 & $103(34.2 \%)$ & $198(65.8 \%)$ & \\
\hline Women & 301 & $89(29.6 \%)$ & $212(70.4 \%)$ & \\
\hline Age (median, IQR) (years) & $68.8(69.9-76.9)$ & $69(60-77)$ & $69(62-77 \%)$ & 0.793 \\
\hline Nationality & & & & 0.019 \\
\hline Spanish & 573 & 177 (30.9\%) & $396(69.1 \%)$ & \\
\hline Other & 29 & $15(51.7 \%)$ & $14(48.3 \%)$ & \\
\hline Education level & & & & 0.925 \\
\hline Without studies & 113 & $34(30.1 \%)$ & 79 (69.9\%) & \\
\hline Primary studies & 245 & 77 (31.4\%) & $168(68.6 \%)$ & \\
\hline Secondary studies & 146 & $50(34.2 \%)$ & $96(65.8 \%)$ & \\
\hline University studies & 93 & 30 (32.3\%) & $63(67.7 \%)$ & \\
\hline Unknown & 5 & $1(20.0 \%)$ & $4(80.0 \%)$ & \\
\hline Civil status & & & & 0.573 \\
\hline Married & 393 & $127(32.3 \%)$ & $266(67.7 \%)$ & \\
\hline Widowed & 126 & $36(28.6 \%)$ & 90 (71.4\%) & \\
\hline Divorced & 48 & $14(43.8 \%)$ & $18(56.3 \%)$ & \\
\hline Single & 32 & $14(29.2 \%)$ & $34(70.8 \%)$ & \\
\hline Unknown & 3 & $1(33.3 \%)$ & $2(66.7 \%)$ & \\
\hline
\end{tabular}

According to the Morisky-Green test, those patients with a change in pill appearance in the previous three refills were less likely to be adherent $(19 / 38,50.0 \%)$ than those with no change in their pharmacological treatments $(373 / 536,69.6 \%)$ or those with a change in the package but not in the pill appearance $(18 / 28,64.3 \%$; $\mathrm{p}=0.039$ ). We also analysed the individual items included in Morisky-Green test in detail: patients with a change in pill appearance paid less attention when taking their medication $(29 / 38,76.3 \%)$ than patients with a change only in their medication package (22/28, $78.6 \%$ ) or those patients with no change in their medication package and/or pill appearance (485/536, $90.5 \% ; \mathrm{p}=0.005)$. Moreover, patients with a change in pill appearance stopped taking their medication more frequently if they felt worse $(5 / 33,13.2 \%)$ than patients with a change only in their medication package (2/28, $7.1 \%$ ) or those patients with no change in their medication package and/or pill appearance (20/536, 3.7\%; $\mathrm{p}=0.020$; data not shown).

In the multivariable analysis (adjusted for nationality, number of drugs per patient, duration of pharmacological treatment, how the patients stored the medication, impact of undesirable adverse effects on leisure activities and convenience of medication use frequency) patients with a previous change in pill appearance were less likely to be adherent than those patients with no change in their pharmacological treatment (adjusted RR 0.45; CI 95\% 0.22 to 0.90; $\mathrm{p}=0.024$; table 4 ).

\section{Impact of changes in pharmacological treatment on the patient's BP}

Patients with a change in the pill appearance in the previous three refills were more likely to have uncontrolled BP $(14 / 38,36.8 \%)$ than those with a change only in the package $(3 / 28,10.7 \%)$ or those with no change in their pharmacological treatment $(144 / 536,26.9 \%$; $\mathrm{p}=0.011)$.

Systolic BP was higher in patients with a change in pill appearance in the previous three refills (median BP $142 \mathrm{~mm} \mathrm{Hg}$; IQR 136-148) than in those with a change only in the package (median BP $134 \mathrm{~mm} \mathrm{Hg}$; IQR 123143 ) or those who did not have a change (median BP 127 mm Hg; IQR 118-135; p<0.001; figure 2).

\section{DISCUSSION}

This study shows a low percentage of adherence in patients who regularly collected their medication (one in three of the patients considered as persistent was described as non-adherent according to the Morisky-Green test) and nearly $15 \%$ of them had uncontrolled BP. Switching between pills of different appearances was associated with a lower adherence to pharmacological treatment (measured through the Morisky-Green test) and a higher percentage of patients with uncontrolled BP (independently of how the patient stored their medication: in its original container or package, in a blister pack or in a pill organiser) than those with no change in their pharmacological treatments or those with a change in the package but not in the pill appearance. Other aspects associated with adherence to pharmacological treatment were patient nationality, educational level, number of medications per patient, duration of pharmacological treatment and the patient's level of satisfaction with medication regarding the impact of the medication on their leisure activities or the schedule for medication use. 
Table 2 Description of the clinical characteristics of the patients included in the study according to the adherence to treatment (according to Morisky-Green test)

\begin{tabular}{|c|c|c|c|c|}
\hline Variable & Total & Non-adherent & Adherent & p Value \\
\hline $\begin{array}{l}\text { Number of medicines/patient }{ }^{\star} \text { (median/IQR) } \\
\text { (minimum } 0 \text { to maximum 12) }\end{array}$ & $4(2-6)$ & & & $<0.001$ \\
\hline$\leq 5$ & 414 & $151(36.5 \%)$ & $263(63.5 \%)$ & \\
\hline$>5$ & 188 & $41(21.8 \%)$ & $147(78.2 \%)$ & \\
\hline Have you ever suffered a cardiovascular event? & & & & 0.734 \\
\hline No & 488 & $159(32.6 \%)$ & 329 (67.4\%) & \\
\hline Yes & 108 & $31(28.7 \%)$ & 77 (71.3\%) & \\
\hline Unknown & 6 & $2(33.3 \%)$ & $4(66.7 \%)$ & \\
\hline When? & & & & 0.540 \\
\hline $0-5$ years & 41 & $11(26.8 \%)$ & $30(73.2 \%)$ & \\
\hline $6-10$ years & 21 & $5(23.8 \%)$ & $16(76.2 \%)$ & \\
\hline $11-15$ years & 10 & $4(40.0 \%)$ & $6(60.0 \%)$ & \\
\hline$>15$ years & 8 & $1(12.5 \%)$ & $7(87.5 \%)$ & \\
\hline Unknown & 28 & $11(37.9 \%)$ & $18(82.1 \%)$ & \\
\hline $\begin{array}{l}\text { Number of diseases/patient* (median/IQR) } \\
\text { (minimum } 0 \text { to maximum } 8 \text { ) }\end{array}$ & $2(1-3)$ & $2(1-2)$ & $2(1-3)$ & 0.057 \\
\hline Active principle & & & & 0.427 \\
\hline Valsartan & 126 & $36(28.6 \%)$ & $90(71.4 \%)$ & \\
\hline Valsartan/hydrochlorothiazide & 135 & $39(28.9 \%)$ & $96(71.1 \%)$ & \\
\hline Telmisartan & 71 & $30(42.3 \%)$ & $41(57.7 \%)$ & \\
\hline Telmisartan/hydrochlorothiazide & 59 & $20(33.9 \%)$ & $39(66.1 \%)$ & \\
\hline Candesartan & 68 & $22(32.4 \%)$ & $46(67.6 \%)$ & \\
\hline Candesartan/hydrochlorothiazide & 48 & $16(33.3 \%)$ & $32(66.7 \%)$ & \\
\hline Irbesartan & 50 & $17(34.0 \%)$ & $33(66.0 \%)$ & \\
\hline Irbesartan/hydrochlorothiazide & 45 & $1(100.0 \%)$ & 0 & \\
\hline What is the medication indicated for? & & & & 0.537 \\
\hline Hypertension & 565 & $183(32.4 \%)$ & $382(67.6 \%)$ & \\
\hline Other answer & 10 & $3(30.0 \%)$ & $7(70.0 \%)$ & \\
\hline Unknown & 27 & $6(22.2 \%)$ & $21(77.8 \%)$ & \\
\hline How long have you been following this treatment? & & & & 0.002 \\
\hline$\leq 6$ months & 26 & $2(7.7 \%)$ & $24(92.3 \%)$ & \\
\hline$>6$ months to 1 year & 27 & $15(55.6 \%)$ & $12(44.4 \%)$ & \\
\hline$>1$ year & 548 & $174(31.8 \%)$ & $374(68.2 \%)$ & \\
\hline Unknown & 1 & $1(100.0)$ & 0 & \\
\hline How do you keep this medicine at home? & & & & 0.815 \\
\hline In its package & 471 & $153(32.5 \%)$ & $318(67.5 \%)$ & \\
\hline In a pillbox & 74 & $20(27.0 \%)$ & 54 (73.0\%) & \\
\hline In its blister & 57 & $19(27.1 \%)$ & $38(66.7 \%)$ & \\
\hline
\end{tabular}

This is the first study that evaluates the impact of this change on individual patient adherence in patients considered as persistent with pharmacological treatment (only patients who had collected their medication in the three previous refills were included in the study). Although changes in pharmacological treatment and appearance discordance occurred infrequently $(6.3 \%)$, differences in pill appearance had an important impact on patient care. Clinical outcomes are affected by how closely patients follow the regimen prescribed (compliance to pharmacological treatment) and also if the patients do not complete the full length of the pharmacological treatment (medication persistence). ${ }^{18}$ Hence, although consistence and persistence are closely related concepts, they cover different aspects in patients' adherence to pharmacological treatment. Given that we only selected patients considered persistent with pharmacological treatment, we were able to detail the factors associated with the extent to which a patient acts in accordance with the prescribed interval and dose of a dosing regimen. Previous studies ${ }^{8}{ }^{9}$ evaluated the impact of a change in pill appearance on the persistence to pharmacological treatment in a population-based analysis. Although in these studies colour and shape discordance also occurred infrequently, the odds of non-persistence in patients increased by $27 \%$ after a change in pill colour.

Previous authors have stated two different reasons that could explain the impact of a change in pill appearance on adherence to pharmacological treatment. ${ }^{8}$ First, 
Table 3 Description of the patients' answers to the Treatment Satisfaction Questionnaire for Medication (TSQM)

\begin{tabular}{|c|c|c|c|c|c|}
\hline Question & 1 & 2 & 3 & 4 & $5^{\star}$ \\
\hline \multicolumn{6}{|l|}{ Undesirable side effects } \\
\hline Impact on physical activities & $551(91.5 \%)$ & $20(3.3 \%)$ & $21(3.5 \%)$ & $5(0.8 \%)$ & $5(0.8 \%)$ \\
\hline Impact on leisure activities & $559(92.9 \%)$ & $17(2.8 \%)$ & $19(3.2 \%)$ & $3(0.5 \%)$ & $4(0.7 \%)$ \\
\hline Impact on daily living activities & $557(92.5 \%)$ & $17(2.8 \%)$ & $21(3.5 \%)$ & $3(0.5 \%)$ & $4(0.7 \%)$ \\
\hline \multicolumn{6}{|l|}{ Impact of treatment on daily living activities } \\
\hline Leisure activities & $34(5.6 \%)$ & $16(2.7 \%)$ & $111(18.4 \%)$ & 227 (37.7\%) & $214(35.5 \%)$ \\
\hline Personal hygiene & $53(8.8 \%)$ & $16(2.7 \%)$ & $134(22.3 \%)$ & $182(30.2 \%)$ & $217(36.0 \%)$ \\
\hline Usual daily activities & $37(6.1 \%)$ & $24(4.0 \%)$ & 109 (18.1\%) & $210(34.9 \%)$ & $222(36.9 \%)$ \\
\hline \multicolumn{6}{|l|}{ Treatment effectiveness } \\
\hline Relief of symptoms & $23(3.8 \%)$ & $24(4.0 \%)$ & $75(12.5 \%)$ & $264(43.9 \%)$ & $216(35.9 \%)$ \\
\hline Time to start working & $28(4.7 \%)$ & $14(2.3 \%)$ & $111(18.4 \%)$ & 239 (39.7\%) & $210(34.9 \%)$ \\
\hline Preventing or treating condition & $27(4.5 \%)$ & $20(3.3 \%)$ & 77 (12.8\%) & 206 (34.2\%) & $272(45.2 \%)$ \\
\hline \multicolumn{6}{|l|}{ Convenience of use } \\
\hline Ease of medication use & $10(1.7 \%)$ & $9(1.5 \%$ & $37(6.1 \%)$ & $173(28.7 \%)$ & $373(62.0 \%)$ \\
\hline Convenience of medication use & $9(1.5 \%$ & $5(0.8 \%)$ & $37(6.1 \%)$ & $171(28.4 \%)$ & $380(63.1 \%)$ \\
\hline Frequency of medication use & $6(1.0 \%)$ & $6(1.0 \%)$ & $23(3.8 \%)$ & 169 (28.1\%) & $398(66.1 \%)$ \\
\hline \multicolumn{6}{|l|}{ Medical care } \\
\hline Medical disease information & $86(14.3 \%)$ & $60(10.0 \%)$ & $68(11.3 \%)$ & 175 (29.1\%) & $213(35.4 \%)$ \\
\hline Treatment disease information & 77 (12.8\%) & $58(9.6 \%)$ & $66(11.0 \%)$ & $183(30.4 \%)$ & $218(36.2 \%)$ \\
\hline \multicolumn{6}{|l|}{ Global satisfaction } \\
\hline $\begin{array}{l}\text { Overall, how confident are you that taking this } \\
\text { medication is a good thing for you? }\end{array}$ & $4(0.7 \%)$ & $7(1.2 \%)$ & $10(1.7 \%)$ & $119(19.8 \%)$ & $462(76.7 \%)$ \\
\hline $\begin{array}{l}\text { How certain are you that the good things about your } \\
\text { medication outweigh the bad things? }\end{array}$ & $6(1.0 \%)$ & $5(0.8 \%)$ & $16(2.7 \%)$ & $154(25.6 \%)$ & $421(69.9 \%)$ \\
\hline $\begin{array}{l}\text { Taking all things into account, how satisfied or } \\
\text { dissatisfied are you with this medication? }\end{array}$ & $4(0.7 \%)$ & $6(1.0 \%)$ & $13(2.2 \%)$ & $161(26.7 \%)$ & $418(69.4 \%)$ \\
\hline
\end{tabular}

Table 4 Multivariable analysis: variables associated with the probability of being adherent to treatment according to the Morisky-Green test

\begin{tabular}{|c|c|c|c|}
\hline Variable & $\mathbf{R R}^{*}$ & $\mathrm{Cl} 95 \%$ & p Value \\
\hline \multicolumn{4}{|l|}{ Nationality } \\
\hline Spanish & 1.00 & & \\
\hline Other & 0.44 & 0.19 to 0.94 & 0.045 \\
\hline \multicolumn{4}{|c|}{ Number of medicines/patient } \\
\hline$<5$ & 1.00 & & \\
\hline$>5$ & 1.77 & 1.02 to 3.09 & 0.044 \\
\hline \multicolumn{4}{|c|}{ How long have you been following this treatment? } \\
\hline$\leq 6$ months & 1.00 & & \\
\hline$>6$ months to 1 year & 0.07 & 0.01 to 0.36 & 0.002 \\
\hline$>1$ year & 0.17 & 0.04 to 0.75 & 0.020 \\
\hline \multicolumn{4}{|c|}{ Has this treatment changed in the past 3 months? } \\
\hline No & 1.00 & & \\
\hline Yes (package) & 0.85 & 0.38 to 1.93 & 0.701 \\
\hline Yes (appearance) & 0.45 & 0.22 to 0.90 & 0.024 \\
\hline \multicolumn{4}{|c|}{ Impact of undesirable adverse effects on leisure activities } \\
\hline No & 1.00 & & 0.605 \\
\hline Yes & 0.58 & 0.07 to 4.57 & \\
\hline \multicolumn{4}{|c|}{ Convenience of medication scheduled } \\
\hline No & 1.00 & & 0.014 \\
\hline Yes & 0.63 & 0.43 to 0.91 & \\
\hline
\end{tabular}

changes in pill appearance can confuse patients. In this study, we were able to demonstrate that those patients with a change in pill appearance were less careful about the time they took their medication. Second, patients can associate the effectiveness of a particular pharmacological treatment with its appearance. ${ }^{19}$ We found that those patients with a change in pill appearance were more likely to stop taking their pharmacological treatment when they felt worse.

It is also important to point out that in Spain (as in most other European countries), medical doctors prescribe the medication in its original package. Given that each particular medication has a distinctive package design, even when the pharmacological treatment is changed to a 'concordant' one (matching pill shape and colour), the package is always different, which can also confuse the patient. However, our results showed that patients' adherence was significantly more influenced by a change in pill appearance than by a change only in the package (adjusted by how the patients kept the medication).

In contrast with previous studies ${ }^{20}$ we found that greater the number of medications prescribed, the higher is the adherence to pharmacological treatment. Given the selection criteria applied in our study (patients who had not discontinued their medication in the three previous refills), the patients may be people 
Figure 2 Description of the impact of changes in treatment on the patient's systolic blood pressure.

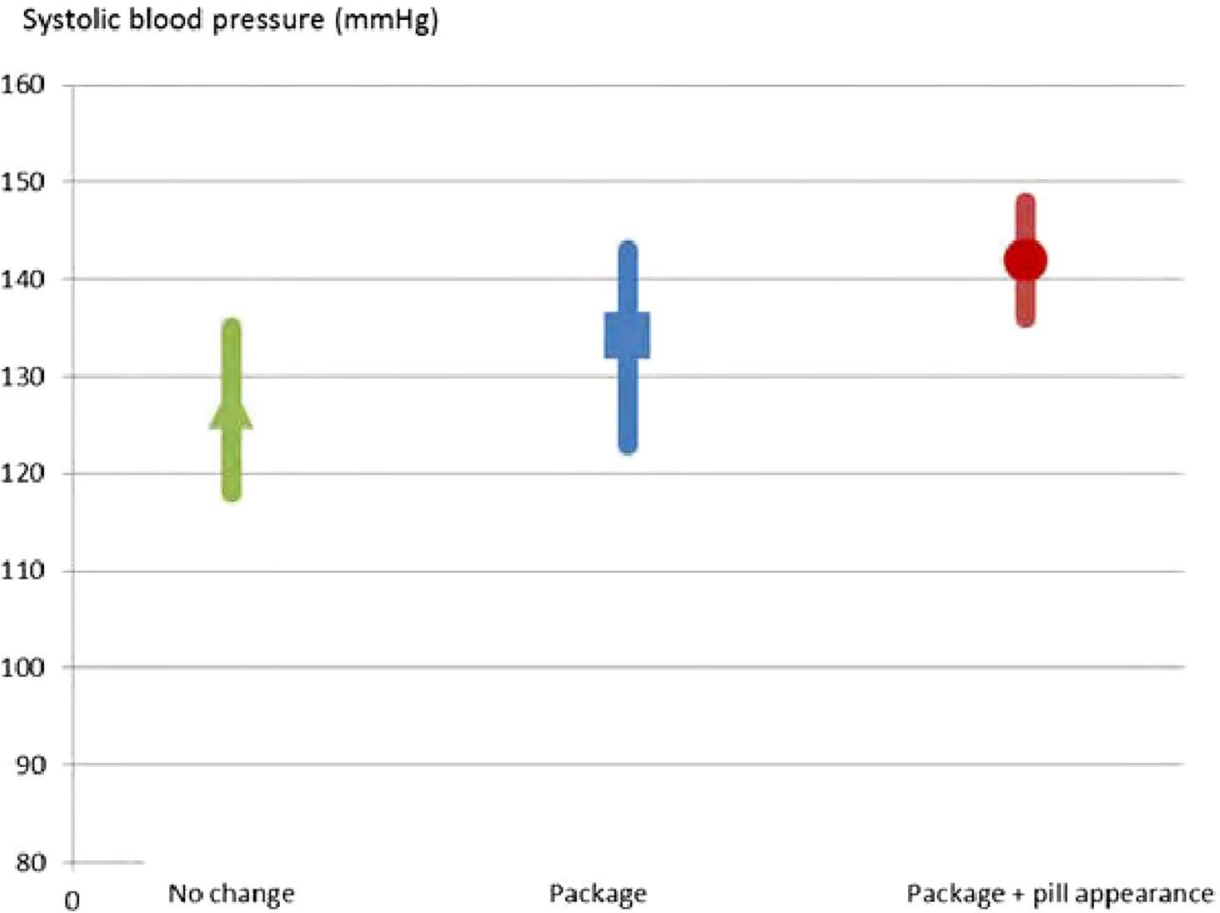

who have a higher awareness of their healthcare and consequently, have developed means to better manage their pharmacological treatment. Within the concept of adherence, acceptance of pharmacological treatment, defined as the patient's decision to agree to it, is also relevant. In our study, adherence increased when patients were in treatment for more than 1 year. This seems to be the minimum time for the patients to accept the treatment and to get used to it. In this sense, the patients' level of satisfaction with medication (measured through the SATMED-Q instrument) may also reflect this acceptance of treatment. Some aspects related with the impact of treatment on the patient's leisure activities or the schedule for medication use, might contribute to this acceptance of their treatment.

This study was carried out in community pharmacies where the findings could have important implications. The pharmacists' role is to optimise each patient encounter to ensure that he/she receives safe and effective medications. However, they should also develop different strategies to increase patients' adherence, for instance, considering the impact of varying treatment appearance. Consequently, pharmacists should tell the patients when their medication has changed and educate them about the safety and efficacy of the drug, independently of its appearance. However, given the increasing frequency of generic medication substitution, they could dispense a pill of a similar size, shape or colour with each refill, whenever possible.

Adherence evaluation is not standardised, and direct methods such as biological assays are difficult to apply. ${ }^{21}$ Other methods, such as pill counts are simple, but they do not guarantee patient collaboration, and thus, may be inaccurate. Questionnaires are the most common method used in clinical settings because they can provide information about a patient's reasons for not adhering to prescribed pharmacological treatments, are easy to use and relatively inexpensive. However, they are indirect methods and therefore, not the most reliable. As in previous studies, ${ }^{22}$ there was no concordance between the Morisky-Green test and the Batalla test. The Morisky-Green test assesses whether the patient takes the right attitudes regarding therapy, but the concept of compliance is very strict and does not include patients with moderate compliance, and it is considered to underestimate adherence. In contrast, the Batalla test has a high specificity but low sensitivity, so it tends to underestimate non-compliance. In this study, we used the Morisky-Green test as the reference test because although it is not ideal, it is validated in Spain to assess the adherence to hypertensive pharmacological treatment. Moreover, we included the measurement of the $\mathrm{BP}$ as a health impact index. Although there was no association between the Morisky-Green test and BP, variations in pill appearance were associated with both the patients' self-reported regimen adherence and BP levels.

We focused our study on patients in pharmacological treatment with ARBs and these results could not apply to patients undergoing different pharmacological treatments.

Inactive ingredients or 'excipients' may differ between the generic medicine and its reference and, although these agents are intended to be inert, they can cause problems in some patients. According to the European Medicine Agency, if precautions are necessary because of an excipient, they are described both on the label and in the package leaflet of the generic medicine and thus, the patients should be aware. Moreover, during the 
course of the study participation, all suspected adverse events (serious and non-serious) had to be collected and recorded in the study database, irrespective of causal association, and they were reported to the local health authority. We did not record any adverse effect in the study.

In conclusion, our study showed a low adherence to pharmacological treatment and a high prevalence of uncontrolled BP in patients who regularly collected their medication from a community pharmacy. Moreover, those patients with a change in pill appearance in the previous three refills were less likely to be adherent than those with no change in their treatments or those with a change in the package but not in the pill appearance. These data underline the need for attention to appearance of pill treatment during the medication prescription and dispensation in the community pharmacy.

Acknowledgements Díaz Álvarez, Alejandro, Álvarez Asencio, Fernando (from the Community Pharmacy Álvarez Asencio), Miralles Llopis, Antonia (from the Community Pharmacy Antonia Miralles), Vicente Gómez, Asunción (from the Community Pharmacy Asunción Vicente Gómez), García Bovet, Montserrat (from the Community Pharmacy Bovet), Brotons Oliver, Alberto (from the Community Pharmacy Brotons), Cano, Miguel (from the Community Pharmacy Cano), Forner Hernéndez, Carlos (from the Community Pharmacy Carmen Pajares), Castelló Arberola, María Dolores (from the Community Pharmacy Castelló Arberola), Catalá Dala, Alejandra (from the Community Pharmacy Catalá), Cristina Fernández-Peinado Martínez (from the Community Pharmacy Cayetano Chazarra), Pomares Miralles, Laura (from the Community Pharmacy del Mar), Salas Devesa, Bernardo (from the Community Pharmacy Devesa), Córcoles Ferrándiz, María Edelmira and Monllor Córcoles, Blanca Fátima (from the Community Pharmacy Edelmira Córcoles), Puig Sapena, Ana María, Soler Garrido, Anna and Trives Lombardero, Eduardo Luis (from the Community Pharmacy Eduardo Trives), Llopis Miró, María Teresa (from the Community Pharmacy El Salt), Arocas Ruiz, Noelia, García Zaragoza, Eugenia, Puerta Rodriguez, María Dolores and Soler Saura, Jose Luis (from the Community Pharmacy Eugenia García Zaragoza), De Dios Gómez, María Nieves and Fe Ballestero Ferrer (from the Community Pharmacy Fe Ballestero), Fos Domínguez, Juan José (from the Community Pharmacy Fos Domínguez), García Espinosa, Almudena (from the Community Pharmacy Francisco Javier Espinós), Franco Lago, Grazinda (from the Community Pharmacy Franco), Alonso Garre, Carlos, González Valdivieso, María and Verdú Calvo, Jordi (from the Community Pharmacy La Barbera), Lanau Cremades, Ana (from the Community Pharmacy Lanau), Herrero López-Gasco, Alfredo (from the Community Pharmacy López-Gasco), López Lloret, María José (from the Community Pharmacy María José Lloret), Martínez Guinea, Diego (from the Community Pharmacy Martínez Guinea), Maurandi Barberá, Nuria (from the Community Pharmacy Maurandi), Maciá Gómez, Carlos, Mora Ortiz de Apodaca, Jose Joaquin and Mora Ortiz de Apodaca, Pablo (from the Community Pharmacy Mora), Mud Castelló, Fernando, Mud Castelló, Sara, Rodríguez Moncho, Ma José and Signes Mut, Almudena (from the Community Pharmacy Ondara), Domínguez Pons, Paloma (from the Community Pharmacy Paloma Dominguez), Pedrajas Pastro, Fernando (from the Community Pharmacy Pedrajas), Griñán Pozo, Jose Javier and Pérez Belda, Elena (from the Community Pharmacy Pérez Belda), Perseguer Torregrosa, Zeneida (from the Community Pharmacy Perseguer Torregrosa), Escoda Viera, Arancha, Piera Vicens, Vanessa and Prats Mas, Rosa (from the Community Pharmacy Rosa Prats), Crespo Sanchez, Francisco Eugenio, Ruiz Lozano, Francisca, Sala Doló, M ${ }^{a}$ Ángeles, Sánchez García, Cristina, Tomás Martínez Rueda, Tomás and Triñanjes Hijarrubia, Ana (from the Community Pharmacy Ruiz Lozano), Santías Samperio, Javier (from the Community Pharmacy Santías), Suárez Bárcena, Eduardo (from the Community Pharmacy Suárez Bárcena), Lloret Pajares, David (from the Community Pharmacy Tomás Lloret), Torregrosa, Jose Vicente (from the Community Pharmacy Torregrosa), Vallejo Ramos, Jaime (from the Community Pharmacy
Vallejos), Puig, Vicente and Seguí García, Miriam (from the Community Pharmacy Vicente Puig).

Contributors BL and EL-P conceived of and designed the study, and obtained funding. $B L$ and $E L-P$ acquired the data. $B L$ prepared the data and $B L$ and EL-P interpreted statistical analyses. EL-P coordinated the data management, and $B L$ wrote the study protocol. BL did the statistical analyses and drafted the data tables. BL and EL-P co-wrote the manuscript. All authors critically revised the paper for important intellectual content and approved the final version.

Funding The study was supported by Sandoz, the generic pharmaceuticals division of Novartis.

Competing interests None declared.

\section{Patient consent Obtained.}

Ethics approval The study was approved by the Institutional Review Board at San Juan Alicante Hospital, Alicante, Spain and by the Spanish Medicines Agency.

Provenance and peer review Not commissioned; externally peer reviewed.

Data sharing statement No additional data are available.

Open Access This is an Open Access article distributed in accordance with the Creative Commons Attribution Non Commercial (CC BY-NC 4.0) license, which permits others to distribute, remix, adapt, build upon this work noncommercially, and license their derivative works on different terms, provided the original work is properly cited and the use is non-commercial. See: http:// creativecommons.org/licenses/by-nc/4.0/

\section{REFERENCES}

1. National Institute for Health and Clinical Excellence (NICE). The clinical management of primary hypertension in adults. NICE Clinical Guideline 127. London: NICE, August 2011.

2. Bloom BS. Continuation of initial antihypertensive medication after 1 year of therapy. Clin Ther 1998;20:671-81.

3. Naderi SH, Bestwick JP, Wald DS. Adherence to drugs that prevent cardiovascular disease: meta-analysis on 376,162 patients. Am J Med 2012;125:882-7.

4. Håkonsen $\mathrm{H}$, Eilertsen $\mathrm{M}$, Borge $\mathrm{H}$, et al. Generic substitution: an additional challenge for adherence in hypertensive patients? Curr Med Res Opin 2009;25:2515-21.

5. Greene JA, Kesselheim AS. Why do the same drugs look different? pills, trade dress, and public health. N Engl J Med 2011;365:83-9.

6. Andersson K, Bergstrøm G, Petzold MG, et al. Impact of a generic substitution reform on patients' and society's expenditure for pharmaceuticals. Health Policy 2007:81:376-84.

7. U.S. Food and Drug Administration. http://www.fda.gov/Drugs/ NewsEvents/ucm471446.htm. Acceded April 2016.

8. Kesselheim AS, Misono AS, Shrank WH, et al. Variations in pill appearance of antiepileptic drugs and the risk of nonadherence. JAMA Intern Med 2013;173:202-8.

9. Kesselheim AS, Bykov K, Avorn J, et al. Burden of changes in pill appearance for patients receiving generic cardiovascular medications after myocardial infarction: cohort and nested case-control studies. Ann Intern Med 2014;161:96-103.

10. Allen LaPointe NM, Ou FS, Calvert SB, et al. Association between patient beliefs and medication adherence following hospitalization for acute coronary syndrome. Am Heart J 2011;161:855-63.

11. Tuppin P, Neumann A, Danchin N, et al. Evidence-based pharmacotherapy after myocardial infarction in France: adherence-associated factors and relationship with 30-month mortality and rehospitalization. Arch Cardiovasc Dis 2010;103:363-75.

12. Mc Namara KP, George J, O'Reilly SL, et al. Engaging community pharmacists in the primary prevention of cardiovascular disease: protocol for the Pharmacist Assessment of Adherence, Risk and Treatment in Cardiovascular Disease (PAART CVD) pilot study. BMC Health Serv Res 2010;10:264.

13. Albrecht G, Hoogstraten J. Satisfaction as a determinant of compliance. Community Dent Oral Epidemiol 1998;26:139-46.

14. Piñeiro Chousa F, Gil Guillén VF, Donis Otero M, et al. Validity of 6 indirect methods in the evaluation of compliance to drug treatment of non-insulin dependent diabetes mellitus. Rev Clin Esp $1997 ; 197: 555-9$. 
15. Morisky DE, Green LW, Levine DM. Concurrent and predictive validity of a self-reported measure of medication adherence. Med Care 1986;24:67-74.

16. Mancia G, Fagard R, Narkiewicz K, et al. 2013 ESH/ESC guidelines for the management of arterial hypertension: the Task Force for the Management of Arterial Hypertension of the European Society of Hypertension (ESH) and of the European Society of Cardiology (ESC). Eur Heart $J$ 2013;34:2159-219.

17. Rejas J, Ruiz M, Pardo A, et al. Detecting changes in patient treatment satisfaction with medicines: the SATMED-Q. Value Health 2013;16:88-96
18. Miller FG, Colloca L, Kaptchuk TJ. The placebo effect: illness and interpersonal healing. Perspect Biol Med 2009;52:518-39.

19. Ngoh LN. Health literacy: a barrier to pharmacist-patient communication and medication adherence. J Am Pharm Assoc 2009;49:e132-46.

20. Bastos-Barbosa RG, Ferriolli E, Moriguti JC, et al. Treatment adherence and blood pressure control in older individuals with hypertension. Arq Bras Cardiol 2012;99:636-41.

21. Lam WY, Fresco P. Medication adherence measures: an overview. Biomed Res Int 2015;2015:217047.

22. Hamilton GA. Measuring adherence in a hypertension clinical trial. Eur J Cardiovasc Nurs 2003;2:219-28. 